This item was submitted to Loughborough's Research Repository by the author.

Items in Figshare are protected by copyright, with all rights reserved, unless otherwise indicated.

\title{
Production of liposomes using microengineered membrane and co-flow microfluidic device
}

PLEASE CITE THE PUBLISHED VERSION

http://dx.doi.org/10.1016/j.colsurfa.2014.03.016

PUBLISHER

(C) Elsevier

VERSION

AM (Accepted Manuscript)

LICENCE

CC BY-NC-ND 4.0

\section{REPOSITORY RECORD}

Vladisavljevic, Goran T., Abdallah Laouini, Catherine Charcosset, Hatem Fessi, Hemaka C.H. Bandulasena, and R.G. Holdich. 2014. "Production of Liposomes Using Microengineered Membrane and Co-flow Microfluidic Device". figshare. https://hdl.handle.net/2134/14323. 
This item was submitted to Loughborough's Institutional Repository (https://dspace.lboro.ac.uk/) by the author and is made available under the following Creative Commons Licence conditions.

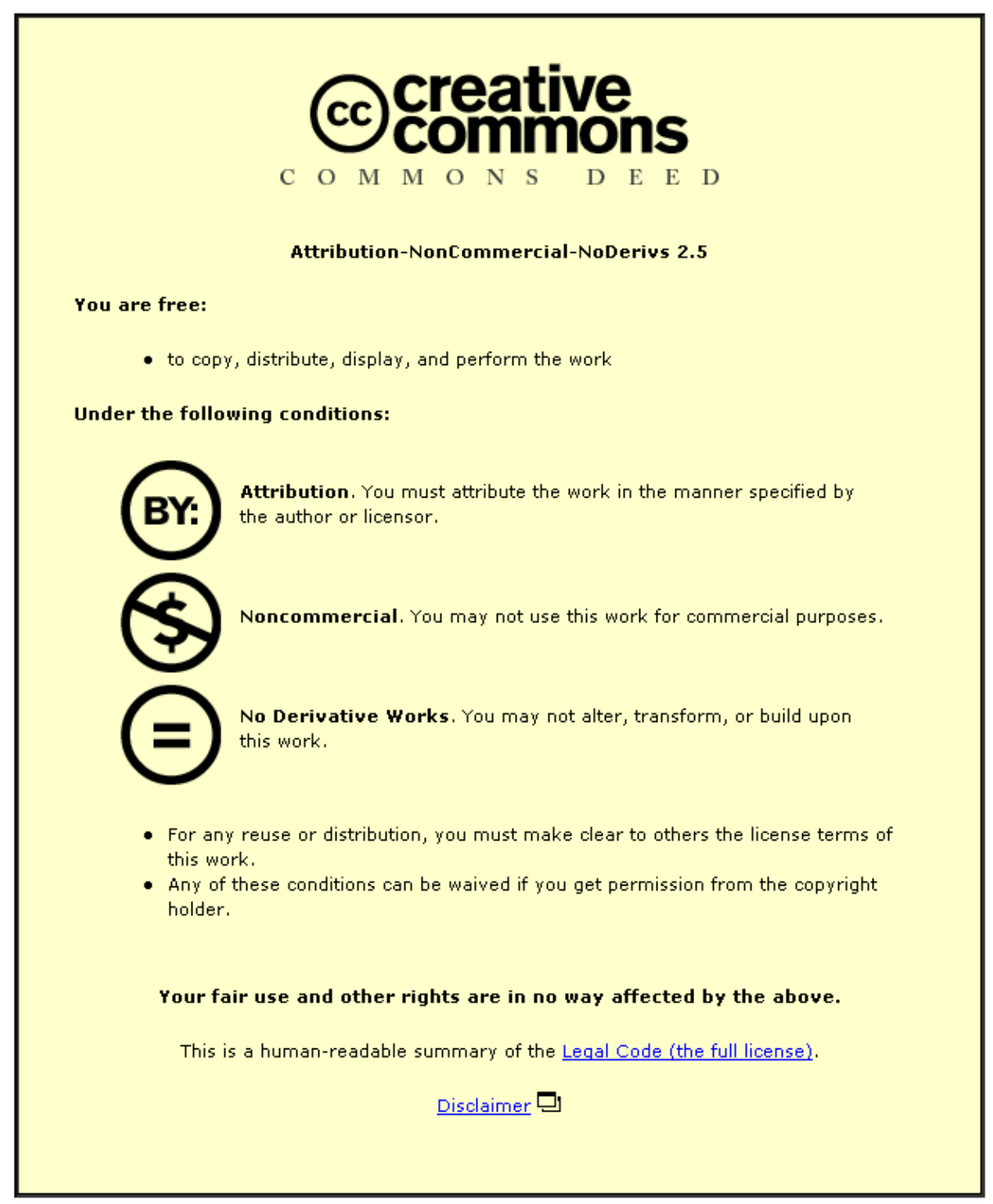

For the full text of this licence, please go to: http://creativecommons.org/licenses/by-nc-nd/2.5/ 


\title{
Production of liposomes using microengineered membrane and co-flow microfluidic device
}

Goran T. Vladisavljević ${ }^{*}$, Abdallah Laouini ${ }^{1,2}$, Catherine Charcosset ${ }^{2}$, Hatem Fessi ${ }^{2}$, Hemaka C.H. Bandulasena $^{1}$ and Richard G. Holdich ${ }^{1}$

${ }^{1}$ Chemical Engineering Department, Loughborough University, Loughborough LE11 3TU, UK, G.Vladisavljevic@lboro.ac.uk.

${ }^{2}$ Université Claude Bernard Lyon 1, Laboratoire d'Automatique et de Génie des Procédés (LAGEP), UMR-CNRS 5007, CPE Lyon, Bat 308 G, 43 Boulevard du 11 Novembre 1918, F-69622 Villeurbanne Cedex, France.

*: To whom correspondence should be addressed: g.vladisavljevic@lboro.ac.uk Tel: + 44 (0) 1509 222518; Fax: + 44 (0) 1509223923

\begin{abstract}
Two modified ethanol injection methods have been used to produce Lipoid $^{\circledR}$ E80 and POPC (1-palmitoyl-2-oleoyl-sn-glycero-3-phosphocholine) liposomes: (i) injection of the organic phase through a microengineered nickel membrane kept under controlled shear conditions and (ii) injection of the organic phase through a tapered-end glass capillary into co-flowing aqueous stream using coaxial assemblies of glass capillaries. The organic phase was composed of $20 \mathrm{mg} \mathrm{ml}^{-1}$ of phospholipids and $5 \mathrm{mg} \mathrm{ml}^{-1}$ of cholesterol dissolved in ethanol and the aqueous phase was ultra-pure water. Self-assembly of phospholipid molecules into multiple concentric bilayers via phospolipid bilayered fragments was initiated by interpenetration of the two miscible solvents. The mean vesicle size in the membrane method was $80 \pm 3 \mathrm{~nm}$ and consistent across all of the devices (stirred cell, cross-flow module and oscillating membrane system), indicating that local or temporal variations of the shear stress on the membrane surface had no effect on the vesicle size, on the condition that a maximum shear stress was kept constant. The mean vesicle size in co-flow microfludic device decreased from 131 to $73 \mathrm{~nm}$ when the orifice diameter in the injection capillary was reduced from 209 to $42 \mu \mathrm{m}$ at the aqueous and organic phase flow rate of 25 and $5.55 \mathrm{ml} \mathrm{h}^{-1}$, respectively. The vesicle size was significantly affected by the mixing efficiency, which was controlled by the orifice size and liquid flow rates. The smallest vesicle size was obtained under conditions that promote the highest mixing rate. Computational Fluid Dynamics (CFD) simulations were performed to study the mixing process in the vicinity of the orifice.
\end{abstract}

\section{Key words}

Liposome • Laminar co-flow $\bullet$ Micromixing $\bullet$ CFD simulation $\bullet$ Microfluidic mixer $\bullet$ Membrane dispersion. 


\section{Introduction}

Liposomes are spherical core-shell structures with a diameter ranging from $20 \mathrm{~nm}$ to several micrometres, composed of concentric bilayers resulting from the self-assembly of phospholipids in an aqueous solution [1]. The polar head groups of phospholipids are located at the surface of the bilayer membranes, whereas the fatty acid chains form the hydrophobic core of the membranes. Liposomes can be multi-, oligo- or unilamellar, containing many, a few, or one bilayer shell(s), respectively. Because of the ability of liposomes to encapsulate both hydrophobic and hydrophilic actives, selectively transport molecules across the bilayer(s), and attach site-specific ligands and stabilizing polymers to their surface, liposomes hold great potential as carriers and/or delivery vehicles for pharmaceuticals [2], enzymes [3], genes [4], and gases [5], and as micro/nano-reactors for biomedical applications [6]. Conventional liposome formation techniques such as lipid film hydration and solvent dispersion methods (e.g. ethanol or ether injection) rely on the mechanical dispersion of dried lipids or rapid dilution of organic lipid solutions in an aqueous environment under non-uniform mechanical shear. In the traditional ethanol injection method [7], an ethanol solution of lipids is rapidly injected through a syringe into a stirred aqueous phase. Because of the single injection point, the mixing occurs as a result of both bulk motion in the aqueous phase (convection or macromixing) and molecular or eddy diffusion (micromixing) (Fig. 1a). Due to irregular shear-stress profile in the vessel and variable mixing length scales, this method typically leads to the formation of polydisperse population of vesicles. Monodispersed liposomes can be produced by utilising $\mathrm{W} / \mathrm{O}$ or $\mathrm{W} / \mathrm{O} / \mathrm{W}$ emulsions as templates to generate the vesicles [8, 9]. However, emulsion templating methods are complicated and used primarily for production of giant liposomes with a vesicle diameter above $1 \mu \mathrm{m}$. Uniform liposomes with a mean diameter ranging from 50 to $300 \mathrm{~nm}$ were produced using microfluidic flow focusing in 2D microchannels fabricated on a silicon wafer by photolithography and Deep Reactive Ion Etching [10] or anisotropic wet etching [11]. However, these fabrication processes are relatively expensive and time consuming, the flow rate of the product stream was only 25-100 $\mu \mathrm{min}^{-1}$, and the flow conditions at the interface between the two phases were not uniform due to $2 \mathrm{D}$ geometry of the outlet channel and its high aspect ratio of 5 . There is a need for the cheaper microfluidic devices for controlled formation of liposomes that can be used at higher production rates.

In this work, two novel microfluidic strategies for liposome formation were used: (i) injection of ethanolic lipid solution through a microengineered membrane kept under controlled shear-stress conditions; (ii) injection of ethanolic phase through a tapered-end capillary into co-flowing aqueous phase using coaxial assembly of glass capillaries. Coaxial glass capillary devices have been used for making emulsions [12], microparticles [13], and giant vesicles [9]; however, so far, these devices have not yet been used for production of nano-sized vesicles. 
It is the first time that formation of liposomes was investigated experimentally and numerically in glass capillary devices. Due to their 3D (axisymmetric) geometry and transparent walls, the flow conditions were uniform over the entire interfacial area and the mixing process was visually observed and recorded by a high-speed camera. Jahn et al. [14] developed a capillary-based method for formation of liposomes that combine hydrodynamic flow focusing with rapid freezing of the product stream. However, liposomes were formed in a non-transparent brass capillary, so the process could not be observed in real time.

In the membrane micromixing process, the mixing occurs only at the microscale level, because the membrane provides numerous micro-injection points to finely disperse organic phase into the aqueous phase without intermediate macromixing stage (Fig. 1b). Membrane emulsification also involves injection of organic phase into the aqueous phase $[15,16]$, but in membrane micromixing the organic solvent and aqueous phase are completely miscible and the process does not result in the formation of organic phase droplets. Liposomes were previously prepared using polymeric hollow fibre and Shirasu Porous Glass (SPG) membranes in cross-flow configuration [17, 18]. However, both membrane types have a sponge-like structure with irregularly shaped, interconnected pores, created by phase separation [19]. In this work, we have used microengineered membranes consisting of evenly spaced, unconnected pores of uniform size and regular cylindrical cross section. Microengineered membranes have been recently used for production of liposomes and micelles [20, 21]. In this work, for the first time the experimental data obtained in membrane and microfluidic devices are compared for the same product formulation.

\section{Material and methods}

\subsection{Reagents}

Phospholipids used in this work were POPC (1-palmitoyl-2-oleoyl-sn-glycero-3-phosphocholine) and Lipoid® E80 (egg yolk lecithin which contains $82 \%$ of phosphatidyl-choline and $9 \%$ of phosphatidyl-ethanolamine), both purchased from Lipoïd GmbH (Ludwigshafen, Germany). Cholesterol supplied from Sigma-Aldrich Chemicals (Saint Quentin Fallavier, France) was used as a stabiliser of phospholipid bilayers. $95 \%$ analytical-grade ethanol supplied by Fisher Scientific (United Kingdom) was used as a volatile organic solvent to dissolve lipids prior to injection. Ultra-pure water was obtained from a Millipore Synergy® system (Ultrapure Water System, Millipore) and used as a dilution medium for organic lipid solutions.

\subsection{Membrane dispersion devices}

The membranes used were nickel membranes with a pore size of $5 \mu \mathrm{m}$ and pore spacing of $200 \mu \mathrm{m}$, fabricated using UV-LIGA (Ultraviolet Lithography, Electroplating, and Molding) technology [22], supplied by Micropore Technologies Ltd. (Hatton, Derbyshire, UK). Three different membrane rigs were used, as shown in Fig. 2. In the stirred cell (Fig. 2a), the aqueous phase was agitated by a paddle-blade stirrer attached above the membrane and the organic phase was injected through the 
membrane using a peristaltic pump (Watson Marlow 101U, Cornwall, UK). The effective diameter of the membrane was $3.3 \mathrm{~cm}$ and a corresponding membrane area was $8.55 \mathrm{~cm}^{2}$. The cross flow module (Fig. 2b) contained a flat membrane with 4 separate active regions, each with a diameter of $7 \mathrm{~mm}$, providing the total membrane area of $1.54 \mathrm{~cm}^{2}$. A shear stress was provided by recirculating the aqueous phase above the membrane surface through a cross-flow channel, $20 \mathrm{~mm}$ wide and 1 $\mathrm{mm}$ high. The organic phase was injected through the membrane using a syringe pump (Havard Appartus 11 Plus), while a peristaltic pump (Watson Matlow 603S) was used to recycle the aqueous phase between the module and an aqueous phase tank. The oscillating membrane rig (Fig. 2c) was composed of a ring membrane with a diameter of $30 \mathrm{~mm}$, a height of $20 \mathrm{~mm}$, and an effective area of $34.1 \mathrm{~cm}^{2}$. The oscillation signal was provided by an audio generator (Rapid Electronics), which fed a power amplifier driving the electro-mechanical oscillator on which the inlet manifold and membrane were mounted. The injection manifold had internal drillings to allow passage of the organic phase by a syringe pump (Harvard Apparatus 11 Plus).

Experimental procedure. In all membrane devices the organic phase was a lipid mixture composed of $20 \mathrm{mg} \mathrm{ml}^{-1}$ POPC and $5 \mathrm{mg} \mathrm{ml}^{-1}$ cholesterol dissolved in ethanol. The stirred cell was filled with $60 \mathrm{ml}$ of ultrapure water and agitated at $600 \mathrm{rpm}$, followed by injection of $13 \mathrm{ml}$ of the organic phase through the membrane at $2 \mathrm{ml} \mathrm{min}^{-1}$. In the cross-flow system, overall $107 \mathrm{ml}$ of the organic phase was injected through the membrane at $36 \mathrm{ml} \mathrm{min}^{-1}$ into $480 \mathrm{ml}$ of the aqueous phase recirculating in the system. The recirculating phase flow rate was maintained at $3700 \mathrm{ml} \mathrm{min}^{-1}$. In the oscillating membrane system, the ring membrane, oscillating with $40 \mathrm{~Hz}$ frequency and $1.2 \mathrm{~mm}$ amplitude, was immersed into a beaker containing $480 \mathrm{ml}$ of the aqueous phase and $107 \mathrm{ml}$ of the organic phase was injected through the membrane at $8 \mathrm{ml} \mathrm{min}^{-1}$. The presence of air bubbles in the inlet tube was avoided during the injection of the organic phase through the membrane. The experimental conditions were so selected to keep in all membrane devices a constant transmembrane flux of $1401 \mathrm{~m}^{-2} \mathrm{~h}^{-1}$, a maximum shear stress on the membrane surface of $4.7 \mathrm{~Pa}$, and an aqueous to organic phase volume ratio before ethanol evaporation of 4.5. The above operating parameters were chosen based on the previously done process optimisation step [20, 23]. After each experiment, the membrane was washed by sonication in ethanol for $1 \mathrm{~h}$, followed by soaking in a siloxane-based wetting agent for $30 \mathrm{~min}$.

The maximum shear stress on the membrane surface was calculated using the equations given in Table 1. The shear stress on the membrane surface in stirred cell varies in the radial direction and has a maximum value at the transitional radius, $r_{\text {trans. }}$ The transitional radius depends on the stirring rate, physical properties of the continuous phase and cell geometry [24] and was $1.1 \mathrm{~cm}$ for the conditions used in this work. In oscillating membrane system, a shear stress on the membrane surface is a sinusoidal function of time and the maximum shear is reached twice during each period of oscillation [25]. In a cross-flow system, shear stress on the membrane surface is neither time nor location dependent and can be controlled by the rate of recirculation of the aqueous phase and the 
dimensions of the cross-flow channel.

\subsection{Co-flow microfluidic device}

The main body of the microfluidic device was made up of two borosilicate glass capillaries: a round inner capillary ( $1 \mathrm{~mm}$ outer diameter and $0.58 \mathrm{~mm}$ inner diameter, Intracel, Royston, UK) and an outer square capillary ( $1 \mathrm{~mm}$ inner dimension, AIT Glass, Rockaway, US). One end of the inner capillary was shaped into a tapering orifice with an inner diameter ranging from 40 to more than $200 \mu \mathrm{m}$. A P-97 Flaming/Brown micropipette puller (Sutter Instrument Co.) was used to produce a sharp tip of about $20 \mu \mathrm{m}$ in diameter. The orifice diameter was then increased by sanding the tip against sandpaper until the orifice with a required size and smooth rim was obtained. A microforge (MF-830, Intracel Ltd.) microscope was used to inspect the orifice size via a built-in scale. The round capillary was then inserted halfway into the square capillary and aligned. Both capillaries were glued onto a microscope slide and two needles (BD Precisionglide ${ }^{\circledR}$, Sigma-Aldrich, O.D. 0.9 $\mathrm{mm}$ ) were glued onto the slide such that the entrances to each capillary were situated inside the hubs (Fig. 3a). A PTFE tubing (I.D. $0.80 \mathrm{~mm}$ ) was used to deliver the organic phase to the inner capillary, while a PE tubing was used to deliver the aqueous phase to the square capillary. Another PTFE tubing (I.D. $1.5 \mathrm{~mm}$ ) was attached to the outlet of the square capillary to transfer the liposomal solution into a vial.

CFD simulations. Computational Fluid Dynamics (CFD) simulations were performed to study flow dynamics and mixing in the vicinity of the orifice. The problem was solved in dimensional form using Comsol Multiphysics $4.3 \mathrm{~b}$. The computational geometry was simplified by considering one fourth of the microfluidic device along the central axis. The length of the square capillary after the orifice was chosen to be sufficiently long (3.5 times the width of the square channel) to avoid end effects affecting the dynamics in the vicinity of the orifice. The model was developed using Laminar Flow model (for fluid flow) and Transport of Concentrated Species (for convection and diffusion). The density and viscosity of water-ethanol solution were determined using the Jouyban-Acree model [26] and the diffusion coefficient was taken as $1 \times 10^{-9} \mathrm{~m}^{2} \mathrm{~s}^{-1}$ [27]. The boundary conditions for the system were specified as no-slip and no flux at walls, velocity and mass fractions at the inlets and pressure boundary at the outlet. The no-slip boundary was assumed based on PIV (particle image velocimetry) measurements of velocity profiles along hydrophilic (uncoated) microchannel glass surface [28]. Computations were carried out using 1,438,532 tetrahedral mesh elements on a Windows workstation following a grid resolution study. The flow ratio between ethanol and water was varied using parametric continuation feature available in the package.

Experimental investigations. In all microfluidic experiments the organic phase was a lipid mixture composed of $20 \mathrm{mg} \mathrm{ml}^{-1}$ Lipoid E80 and $5 \mathrm{mg} \mathrm{ml}^{-1}$ cholesterol dissolved in ethanol. The organic and aqueous phase were delivered from SGE gas tight syringes to their respective capillaries using 
11 Elite syringe pumps (Harvard Apparatus). The micro-scale mixing process then took place in the square capillary as the organic stream was diluted by Milli-Q water. This was observed through a Phantom V9.0 high-speed camera (Ametek, USA) mounted on an inverted microscope (XDS-3, GX Microscopes, UK). The process was recorded with 25 frames per second at $576 \times 288$ resolution and the recordings were analysed using ImageJ software.

\subsection{Analysis and characterisation of samples}

After production, the liposomal suspension was collected and remaining ethanol was removed by evaporation under reduced pressure in a vacuum oven (Buchi, Flawil, Switzerland). The particle size distribution was measured by differential centrifugal sedimentation using a CPS disc centrifuge, model DC 24000 (CPS instruments, Florida, USA). Prior to the analysis, the instrument was calibrated using an aqueous suspension of polybutadiene particles of a known size distribution and a mean size of $402 \mathrm{~nm}$. The mean particle size of liposomes was expressed as the number-average mean diameter, $d_{a v}$ and the polydispersity was expressed as the coefficient of variation, $C V=\left(\sigma / d_{a v}\right)$ $\times 100$, where $\sigma$ is the standard deviation of particle diameters.

\section{Discussion}

\subsection{Membrane dispersion}

The particle size distribution of multilamellar liposomes prepared in different devices is shown in Fig. 4. The mean vesicle size of $80 \pm 3 \mathrm{~nm}$ was consistent across all of the devices, indicating that local or temporal variations of the shear stress on the membrane surface had a negligible effect on the mean vesicle size, on the condition that a maximum shear stress was kept constant. The largest mean vesicle size $\left(\mathrm{d}_{\mathrm{av}}=86 \mathrm{~nm}\right)$ and the widest size distribution $(\mathrm{CV}=36 \%)$ were obtained in the cross flow system, due to the long recirculation time of the liposomal suspension of nearly $300 \mathrm{~min}$, which can lead to deposition of newly formed bilayered fragments onto the surface of the vesicles already present in the suspension. The smallest and most uniform vesicles $\left(\mathrm{d}_{\mathrm{av}}=80 \mathrm{~nm}\right.$ and $\mathrm{CV}=$ $26 \%$ ) were obtained in the oscillating system, which can be attributed to shear stress generated only on the membrane surface, while agitation was negligible in the bulk of the aqueous phase. The fabrication process using oscillating membrane holds greatest potential to be transferred from batch to continuous operation, because hydrodynamic conditions on the membrane surface are independent on the geometry of the cross-flow channel, flow rate above the membrane surface or membrane size. In cross-flow membrane systems, shear stress on the membrane surface is controlled by fluid flow over the membrane surface, which means that the aqueous phase flow rate must be relatively high to generate sufficiently high stress on the membrane surface to achieve satisfactory mixing efficiency. As a result, recirculation of the aqueous phase is inevitable because the liposomal suspension would be too diluted in a single-pass operation. In oscillating membrane system, the shear stress on the membrane surface is decoupled from the cross flow velocity and controlled only by the frequency and amplitude of the membrane oscillation. Thus, very low cross-flow velocities can be used in continuous operation and recirculation of the aqueous stream is 
not needed, which can help to limit secondary interactions between particles in the product stream.

\subsection{Microfluidic vesicle formation}

We have used CFD to simulate flow patterns in the co-flow microfluidic device with an orifice diameter of $\mathrm{D}=209 \mu \mathrm{m}$ at constant organic phase flow rate of $\mathrm{Q}_{\mathrm{o}}=0.6 \mathrm{ml} \mathrm{h}^{-1}$ and a variable water phase flow rate. Fig. 5 shows the velocity field within the device with an orifice diameter of $209 \mu \mathrm{m}$. As expected, the maximum velocity was reached in the centre of the orifice. The organic phase velocity dropped significantly downstream of the orifice compared to the average velocity in the orifice, due to increase in the cross-sectional area and the drag force from the surrounding water phase, because the water phase velocity was lower than that of the organic phase. At $Q_{o}=Q_{w}=0.6$ $\mathrm{ml} \mathrm{h}^{-1}$, the steady-state velocity profile was established within the distance of 2 nozzle diameters from the nozzle. At $Q_{0}=0.6 \mathrm{ml} \mathrm{h}^{-1}$ and $Q_{w}=9 \mathrm{ml} \mathrm{h}^{-1}$, the steady state parabolic velocity profile was established farther downstream, as can be seen from Fig. 6. For the conditions specified in Fig. 6, at a distance of $\mathrm{L}=0.5 \mathrm{D}$ and $\mathrm{L}=\mathrm{D}$ downstream of the orifice, fluid flow exhibits two velocity maxima, corresponding to the maximum velocities in the two phases, and a minimum in between, corresponding to the position of the orifice wall. At $\mathrm{L}=2 \mathrm{D}$, the velocity profile was not yet fully developed with a constant velocity in the central part of the collection tube and a sudden drop near the tube wall. At $\mathrm{L}=12 \mathrm{D}$, a parabolic velocity profile was established over the whole cross section of the tube, as expected for laminar flow conditions.

The distribution of fluid densities in the device is shown in Fig. 7. The orifice size and fluid flow rates are the same as those in Fig. 5. The organic phase forms a jet that extends downstream of the orifice. As the water flow rate increases from 0.6 to $9 \mathrm{ml} \mathrm{h}^{-1}$, the jet gets progressively shorter and thinner. The smaller jet diameters at the higher water flow rates were due to the higher jet velocities, as shown in Fig. 5. The mixing of the two liquids is more efficient at the higher water flow rates, because of the shorter diffusion distances $x$ for thinner jets. In laminar flow, the average time for molecules to diffuse over a distance $\mathrm{x}$ is given by [29]:

$t=x^{2} / 2 D$

where $D$ is the diffusion coefficient. In this study, $x$ is the jet radius and therefore, the mixing time is proportional to the square of the jet radius.

Microscopic images of the mixing process at different flow rates of the two phases are shown in Fig. 8. We have identified three main regimes of fluid flow in the collection capillary: parallel two-phase flow, dripping, and jetting. At low flow rates of both phases, two parallel coexisting streams were formed - organic stream in the central part of the capillary and liposomal suspension in the annular space between the organic stream and the wall (Fig. 8a). The flow pattern was similar to that predicted by the CFD simulation shown in Fig. 7a. The rate of convective transport of ethanol in the 
downstream direction was large compared to the rate of molecular diffusion of ethanol in the radial direction and consequently, the diameter of the organic stream in the square capillary was almost constant. Vesicles were visible in the aqueous phase, because they formed microscopic unstable aggregates, which disappeared upon dilution. Clusters of spherical and flattened lipid structures were also observed by Jahn et al. [14] and their formation was explained by viscous fingering between liquids of different viscosities. As the water flow rate increased from 0.6 to $5 \mathrm{ml} \mathrm{h}^{-1}$, the organic phase formed a short hemispherical jet near the orifice (Fig. 8b). The interface between the organic and water phase was visible due to difference in refractive indices of water (1.33) and ethanol (1.36) and accumulation of phospholipid bilayers at the interface caused by an abrupt change in the ethanol concentration. The position of the interface would be stationary under steady-state conditions, but due to small periodic fluctuations in the flow rates caused by the pumps imperfections, the interface oscillated slightly in the axial direction, which enhanced the interfacial mass transfer. Aggregation of vesicles in the aqueous phase was less pronounced than in the previous case, due to higher dilution of the organic phase.

As the water flow rate increased from 5 to $15 \mathrm{ml} \mathrm{h}^{-1}$, the interface was pulled downstream, forming a cylindrical jet with a diameter approximately equal to the orifice diameter (Fig. 8c). We observed two distinct jet morphologies in the jetting regime. A narrowing jet was generated when the average velocity of the water stream at the orifice was higher that the organic phase velocity $\left(U_{w}>U_{o}\right)$, as shown in Figs. 8d and 8e. In Fig. 8d, $\mathrm{U}_{\mathrm{w}}=4.3 \mathrm{~mm} \mathrm{~s}^{-1}$ and $\mathrm{U}_{\mathrm{o}}=0.8 \mathrm{~mm} \mathrm{~s}^{-1}$. This velocity difference accelerated the jet, causing it to narrow as it moved downstream. The jet was longer at the higher water flow rate, as shown in Figs. 8d and 8e. A good match between CFD simulation and real flow pattern at the same experimental conditions can be seen from Figs. $8 \mathrm{e}$ and $8 \mathrm{f}$.

A widening jet was observed when the organic phase was injected at much higher velocity than the average velocity of the water (Fig. 8g). A high shear at the interface due to large difference in fluid velocity at the outlet of the injection tube $\left(U_{o}=97 \mathrm{~mm} \mathrm{~s}^{-1}, U_{w}=7 \mathrm{~mm} \mathrm{~s}^{-1}\right)$ decelerated the jet, causing it to widen until it was disintegrated. At very high velocities of both phases in the collection capillary and high resulting shear stresses, a vortex was formed in the aqueous phase around a jet, characterised by high concentration of aggregated liposomes (Fig. 8h). Aggregates are presumably formed at the interface between the two liquid phases. They travel along the interface until they reach a point where the jet disintegrates due to hydrodynamic instabilities. The aggregates are then partly pulled back and caught into the vortex and partly pushed forward and carried away by the main stream.

The particle size distribution of liposomes prepared using co-flow capillary devices with a variable orifice size is given in Fig. 9. At the aqueous and organic phase flow rate of 25 and $5.55 \mathrm{ml} \mathrm{h}^{-1}$, respectively, the mean vesicle size decreased from 131 to $73 \mathrm{~nm}$ when the orifice diameter decreased from 209 to $42 \mu \mathrm{m}$. It can be explained by the fact that the organic phase jet got thinner 
when the orifice size was reduced, which reduced significantly the mixing time, according to Eq. (1). The smaller vesicles are formed at the higher mixing efficiency [20].

\section{Conclusions}

Size-controlled liposomes were produced by controlled mixing of ethanolic lipid solutions with water via a microengineered membrane or tapered-end glass capillary. The mean size of liposomes produced in different membrane devices was highly consistent when the maximum shear stress on the membrane surface was kept constant, although temporal or spatial distribution of shear stress in these devices was significantly different. The oscillating membrane system was found to be most suitable for scale-up, because shear stress on the membrane surface was independent on the system geometry, fluid flow rate and membrane size.

A mixing rate in co-flowing laminar streams depends on the morphology of an organic phase jet formed downstream of the injection orifice. A high mixing efficiency and low mixing time associated with small vesicle size were achieved at high flow rates of aqueous phase and/or small orifice diameter. The microfluidic strategies developed in this work can be used for production of a wide range of nanoparticles, such as micelles, gold nanoparticles, biodegradable polymeric nanoparticles, etc.

\section{References}

[1] A.D. Bangham, R.W. Horne, Negative staining of phospholipids and their structural modification by surface-active agents as observed in the electron microscope, J. Mol. Biol. 8 (1964) 660-668.

[2] V.P. Torchilin, Recent advances with liposomes as pharmaceutical carriers, Nat. Rev. Drug Discovery 4 (2005) 145-160.

[3] P. Walde, S. Ichikawa, Enzymes inside lipid vesicles: preparation, reactivity and applications, Biomol. Eng. 18 (2001) 143-177.

[4] N.S. Templeton, D.D. Lasic, P.M. Frederik, H.H. Strey, D.D. Roberts, G.N. Pavlakis, Improved DNA: liposome complexes for increased systemic delivery and gene expression, Nat. Biotechnol. 15 (1997) 647-652.

[5] E. Unger, D. Shen, T. Fritz, B. Kulik, P. Lund, G.L. Wu, D. Yellowhair, R. Ramaswami, T. Matsunaga, Gas filled lipid bilayers as imaging contrast agents, J. Liposome Res. 4 (1994) 861-874.

[6] A. Graff, M. Winterhalter, W. Meier, Nanoreactors from polymer-stabilized liposomes, Langmuir 17 (2001) 919-923.

[7] M.J. Campbell, Lipofection reagents prepared by a simple ethanol injection technique, Biotechniques 18 (1995) 1027-1032. 
[8] T. Kuroiwa, H. Kiuchi, K. Noda, I. Kobayashi, M. Nakajima, K. Uemura, S. Sato, S. Mukataka, S. Ichikawa, Controlled preparation of giant vesicles from uniform water droplets obtained by microchannel emulsification with bilayer-forming lipids as emulsifiers, Microfluid. Nanofluid. 6 (2009) 811-821.

[9] H.C. Shum, D. Lee, I. Yoon, T. Kodger, D.A. Weitz, Double emulsion templated monodisperse phospholipid vesicles, Langmuir 24 (2008) 7651-7653.

[10] A. Jahn, S.M. Stavis, J.S. Hong, W.N. Vreeland, D.L. DeVoe, M. Gaitan, Microfluidic mixing and the formation of nanoscale lipid vesicles, ACS Nano 4 (2010) 2077-2087.

[11] A. Jahn, W.N. Vreeland, M. Gaitan, L.E. Locascio, Controlled vesicle self-assembly in microfluidic channels with hydrodynamic focusing, J. Am. Chem. Soc. 126 (2004) 2674-2675.

[12] A.S. Utada, A. Fernandez-Nieves, J.M. Gordillo, D.A. Weitz, Absolute instability of a liquid jet in a coflowing stream, Phys. Rev. Lett. 100 (2008) Art. No. 014502.

[13] G.T. Vladisavljević, W.J. Duncanson, H.C. Shum, D.A. Weitz, Emulsion templating of poly(lactic acid) particles: droplet formation behavior, Langmuir 28 (2012) 12948-12954.

[14] A. Jahn, F. Lucas, R.A. Wepf, P.S. Dittrich, Freezing continuous-flow self-assembly in a microfluidic device: toward imaging of liposome formation, Langmuir 29 (2013) 1717-1723.

[15] E. Egidi, G. Gasparini, R.G. Holdich, G.T. Vladisavljević, S.R. Kosvintsev, Membrane emulsification using membranes of regular pore spacing: Droplet size and uniformity in the presence of surface shear, J. Membr. Sci. 323 (2008) 414-420.

[16] G.T. Vladisavljević, H. Schubert, Influence of process parameters on droplet size distribution in SPG membrane emulsification and stability of prepared emulsion droplets, J. Membr. Sci. 225 (2003) 15-23.

[17] A. Laouini, C. Jaafar-Maalej, S. Sfar, C. Charcosset, H. Fessi, Liposome preparation using a hollow fiber membrane contactor-Application to spironolactone encapsulation, Int. J. Pharm. 415 (2011) 53-61.

[18] T.T. Pham, C. Jaafar-Maalej, C. Charcosset, H. Fessi, Liposome and niosome preparation using a membrane contactor for scale-up, Colloids Surf., B 94 (2012) 15-21.

[19] G.T. Vladisavljević, M. Shimizu, T. Nakashima, Permeability of hydrophilic and hydrophobic Shirasu-porous-glass (SPG) membranes to pure liquids and its microstructure, J. Membr. Sci. 250 (2005) 69-77.

[20] A. Laouini, C. Charcosset, H. Fessi, R.G. Holdich, G.T. Vladisavljević, Preparation of liposomes: a novel application of microengineered membranes - Investigation of the process parameters and application to the encapsulation of vitamin E, RSC Adv. 3 (2013) 4985-4994.

[21] A. Laouini, K.P. Koutroumanis, C. Charcosset, S. Georgiadou, H. Fessi, R.G. Holdich, G.T. Vladisavljević, pH-Sensitive micelles for targeted drug delivery prepared using a novel membrane contactor method, ACS Appl. Mater. Interfaces 112 (2013) 8939-8947.

[22] G.T. Vladisavljević, I. Kobayashi, M. Nakajima, Production of uniform droplets using membrane, microchannel and microfluidic emulsification devices, Microfluid. Nanofluid. 13 
(2012) 151-178.

[23] A. Laouini, C. Charcosset, H. Fessi, R.G. Holdich, G.T. Vladisavljević, Preparation of liposomes: a novel application of microengineered membranes - Scale-up from laboratory scale to large scale, Colloid. Surf. B. 112 (2013) 272-278.

[24] M.M. Dragosavac, M.N. Sovilj, S.R. Kosvintsev, R.G. Holdich, G.T. Vladisavljević, Controlled production of oil-in-water emulsions containing unrefined pumpkin seed oil using stirred cell membrane emulsification, J. Membr. Sci. 322 (2008) 178-188.

[25] R.G. Holdich, M.M. Dragosavac, G.T. Vladisavljević, S.R. Kosvintsev, Membrane emulsification with oscillating and stationary membranes, Ind. Eng. Chem. Res. 49 (2010) 3810-3817.

[26] I.S. Khattab, F. Bandarkar, M.A.A., Fakhree, A. Jouyban, Density, viscosity, and surface tension of water+ethanol mixtures from 293 to 323 K, Korean J. Chem. Eng. 29 (2012) 812-817.

[27] R.E. Treybal, Mass Transfer Operations, McGraw-Hill Book Company, New York, 1955, p. 25 .

[28] D. Tretheway, C. Meinhart, Apparent fluid slip at hydrophobic microchannel walls, Phys. Fluids 14 (2002) L9-L12.

[29] Z. Zhang, P. Zhao, G. Xiao, Focusing-enhanced mixing in microfluidic channels, Biomicrofluidics 2 (2008) 014101. 
Table 1. Equations for the maximum shear stress at the membrane/aqueous phase interface in different membrane devices as a function of system geometry, process parameters and physical properties of the continuous phase.

\begin{tabular}{|c|l|c|c|}
\hline \multirow{2}{*}{ Membrane set-up } & \multicolumn{1}{|c|}{$\begin{array}{c}\text { Maximum shear stress on } \\
\text { membrane surface }\end{array}$} & \multicolumn{2}{|c|}{ Shear variations } \\
\cline { 3 - 4 } & Temporal & Local \\
\hline Stirred cell & ${ }^{*} \tau_{\max }=\frac{0.825 \eta_{a q} \omega r_{\text {trans }}}{\sqrt{\eta_{a q} /\left(\rho_{a q} \omega\right)}}$ & - & + \\
\hline Cross flow membrane & $\tau_{\max }=\frac{3 Q \eta_{a q}}{2 h^{2} W}$ & - & - \\
\hline Oscillating membrane & $\tau_{\max }=(2 \pi a f)^{3 / 2}\left(\eta_{w} \rho_{w}\right)^{1 / 2}$ & + & - \\
\hline
\end{tabular}

${ }^{*} r_{\text {trans }}=1.23 \frac{D_{s}}{2}\left(0.57+0.35 \frac{D_{s}}{T}\right)\left(\frac{b}{T}\right)^{0.036} n_{b}{ }^{0.116} \mathrm{Re} /(1000+1.43 \mathrm{Re})$

In this work: $\mathrm{b}=12 \mathrm{~mm}, \mathrm{D}_{\mathrm{s}}=32 \mathrm{~mm}, \mathrm{~h}=1 \mathrm{~mm}, \mathrm{~T}=40 \mathrm{~mm}, \mathrm{~W}=20 \mathrm{~mm}$.

\section{Nomenclature}

$a$

$b$

$D$

$D_{s}$

$f$

$h$

$n_{b}$

$r_{\text {trans }}$

$Q$

$R e$

$T$

W

$\eta_{w}$

$\rho_{w}$

$\omega$

$\tau_{\max }$
Amplitude of membrane oscillation, $\mathrm{m}$

Height of stirrer blade, $m$

Orifice diameter, $m$

Stirrer diameter, $m$

Frequency of membrane oscillation, $\mathrm{Hz}$

Height of cross flow channel, m

Number of stirrer blades, -

Radial distance from the axis of rotation at which the shear is maximal, $m$

Volume flow rate in cross-flow channel, $\mathrm{m}^{3} \mathrm{~s}^{-1}$

Rotating Reynolds number of continuous phase $\left(=\omega \rho_{c} D_{s}{ }^{2} /\left(2 \pi \eta_{c}\right)\right)$

Internal diameter of stirred cell, $\mathrm{m}$

Width of cross flow channel, $\mathrm{m}$

Viscosity of aqueous phase, $\mathrm{Pa} \mathrm{s}$

Density of aqueous phase, $\mathrm{kg} \mathrm{m}^{-3}$

Angular velocity of stirrer, $\operatorname{rad~s}^{-1}$

Maximum shear stress on membrane surface, $\mathrm{Pa}$ 


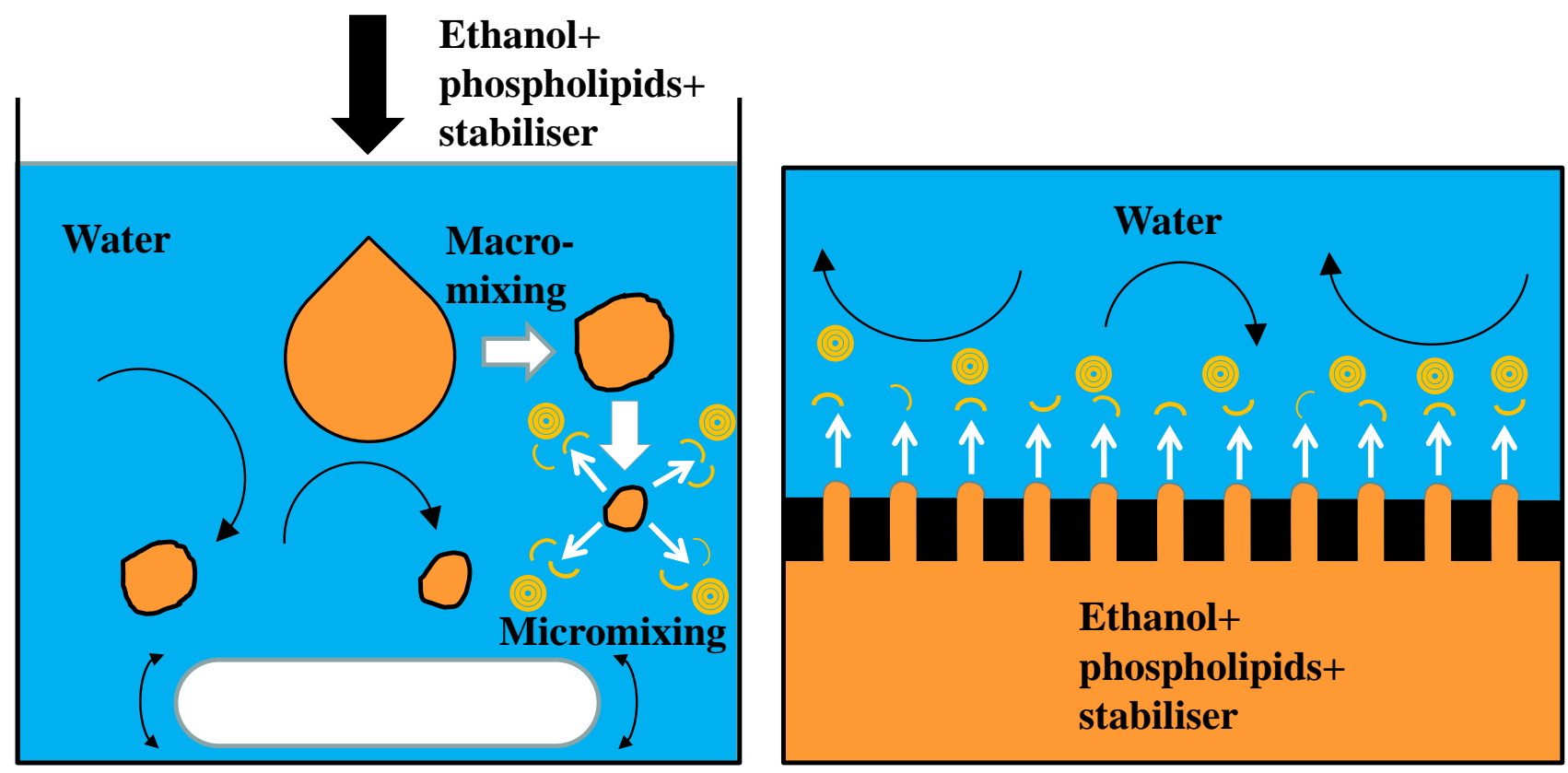

Figure 1. Liposome production by the ethanol injection method: (a) direct dissolution (macromixing + micromixing); (b) membrane injection (direct micromixing). 
(a)

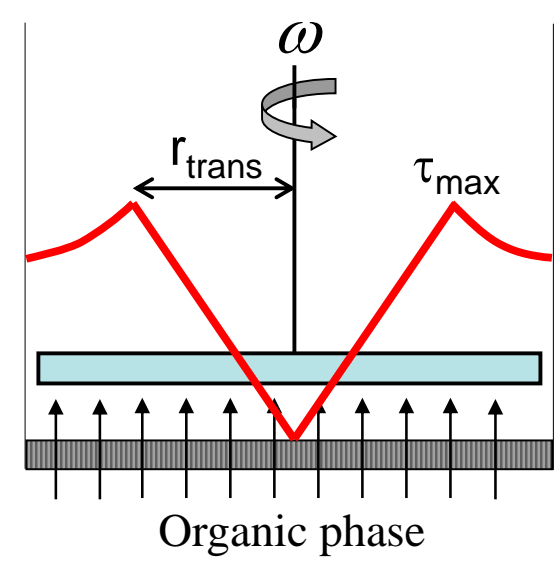

(b)

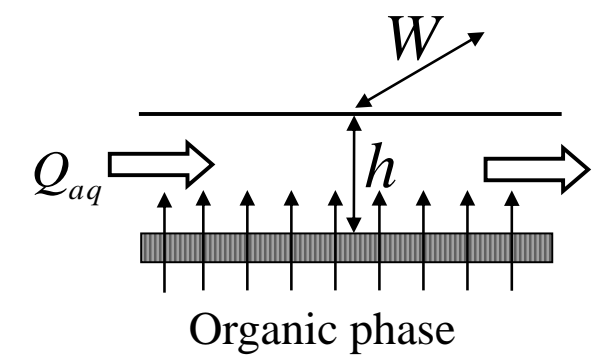

(c)

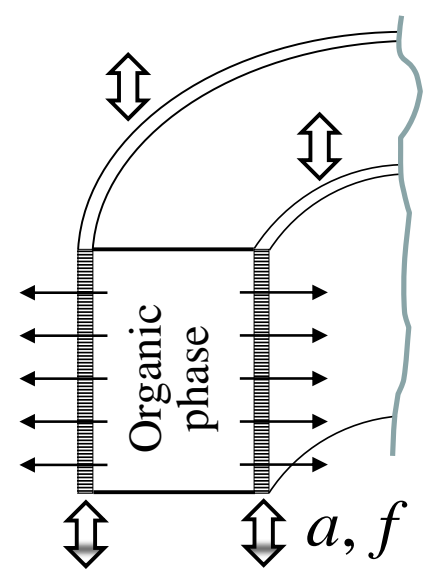

Figure 2. Membrane devices used in this work supplied by Micropore Technologies Ltd. (Hatton, Derbyshire, UK): (a) stirred cell (Dispersion Cell); (b) cross-flow membrane system; (c) vibrating ring membrane. The red line in figure (a) shows the distribution of the shear stress on the membrane surface. 
(a)

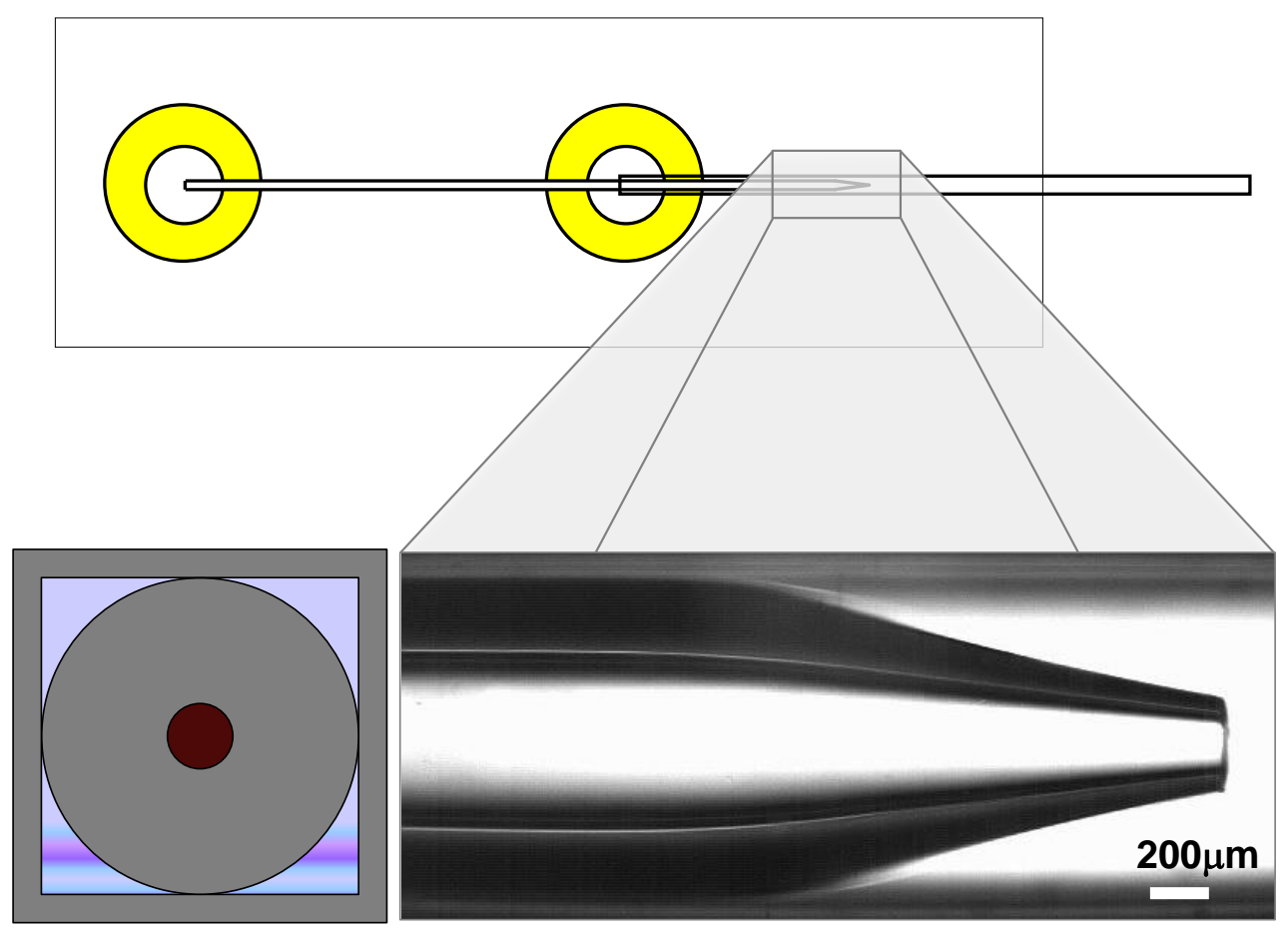

(b)

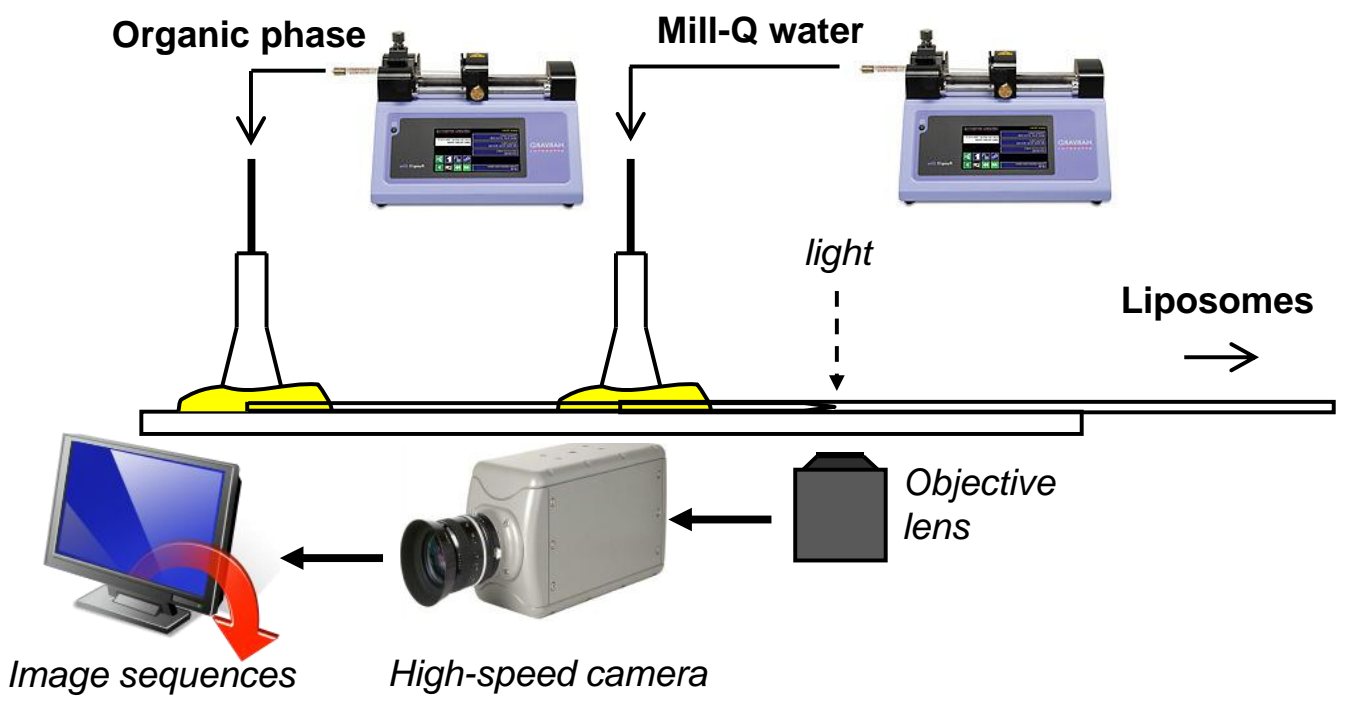

Figure 3. Microfluidic co-flow device consisted of coaxial assembly of glass capillaries glued onto a microscope slide: (a) Top view and microscopic image of a tapered section of the inner capillary with $209 \mu \mathrm{m}$ orifice diameter; (b) side view of the device and the experimental set-up. 


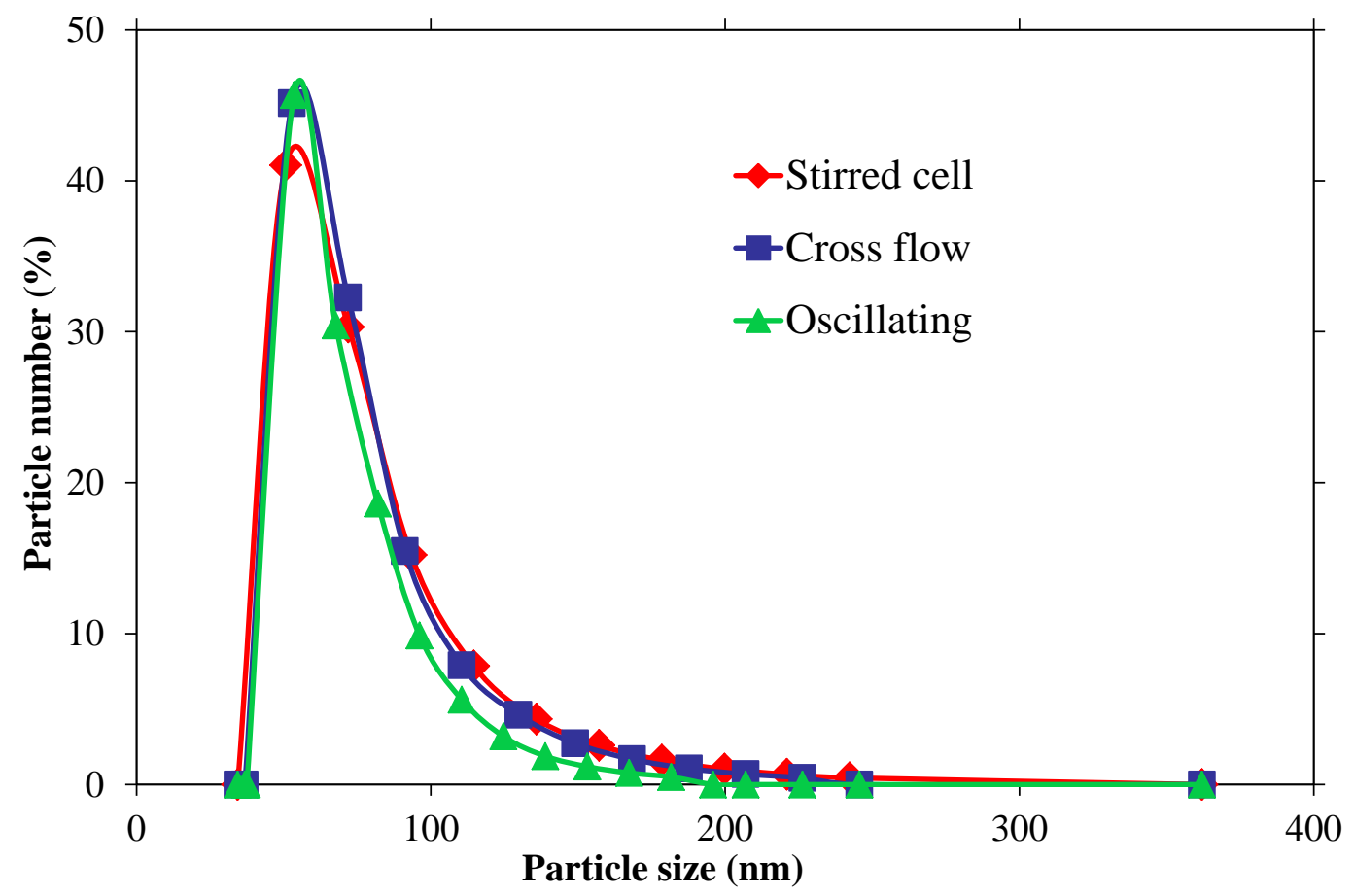

Figure 4. Particle size distribution of liposomal suspensions prepared using three different membrane dispersion devices. 


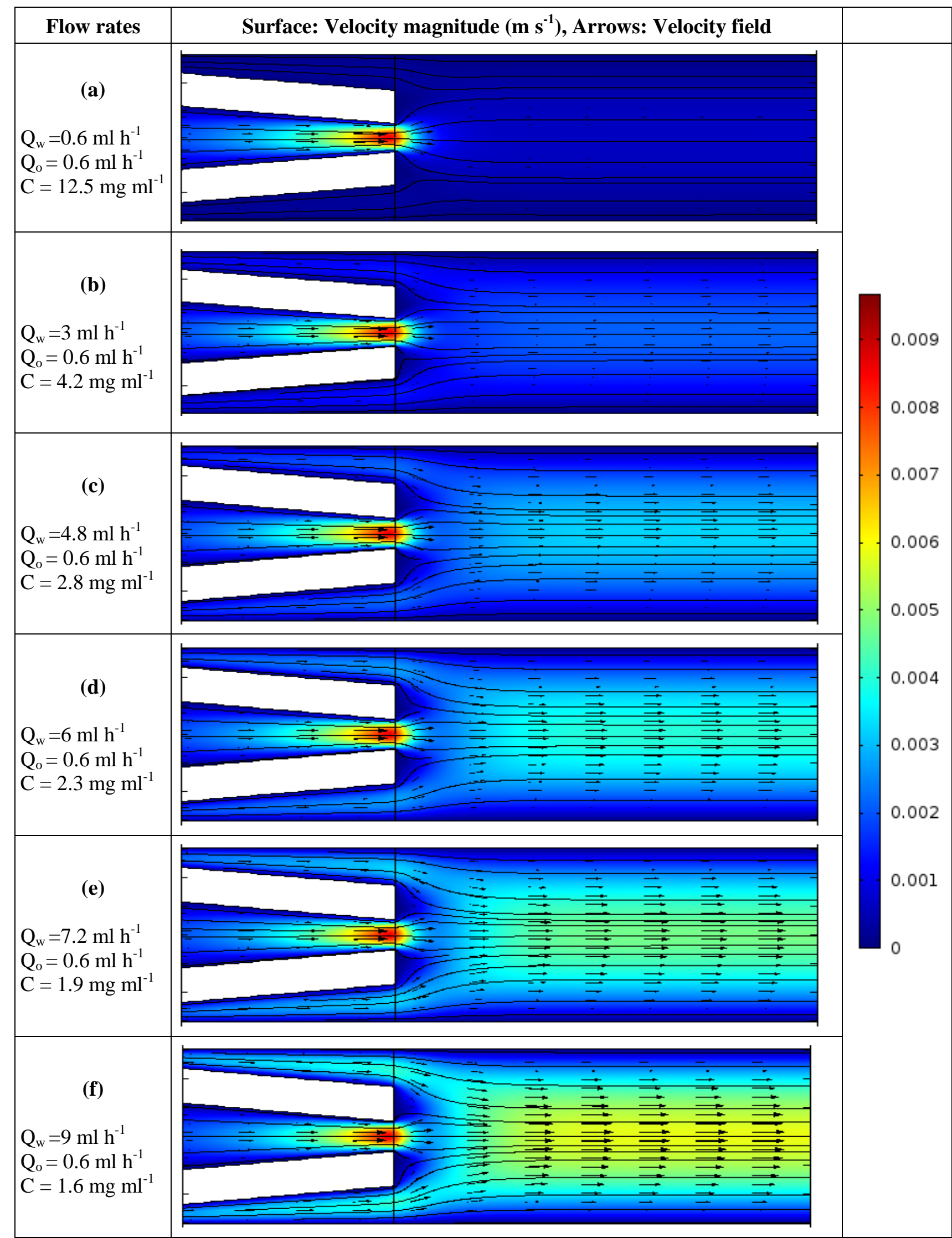

Figure 5. Distribution of fluid velocities in co-flow capillary device at the organic phase flow rate, $Q_{0}$, of $0.6 \mathrm{ml} \mathrm{h}^{-1}$ and increasing water flow rate, $Q_{w}$. The orifice diameter is $\mathrm{D}=209 \mu \mathrm{m}$. $\mathrm{C}$ is the calculated concentration of lipids in the product stream. 


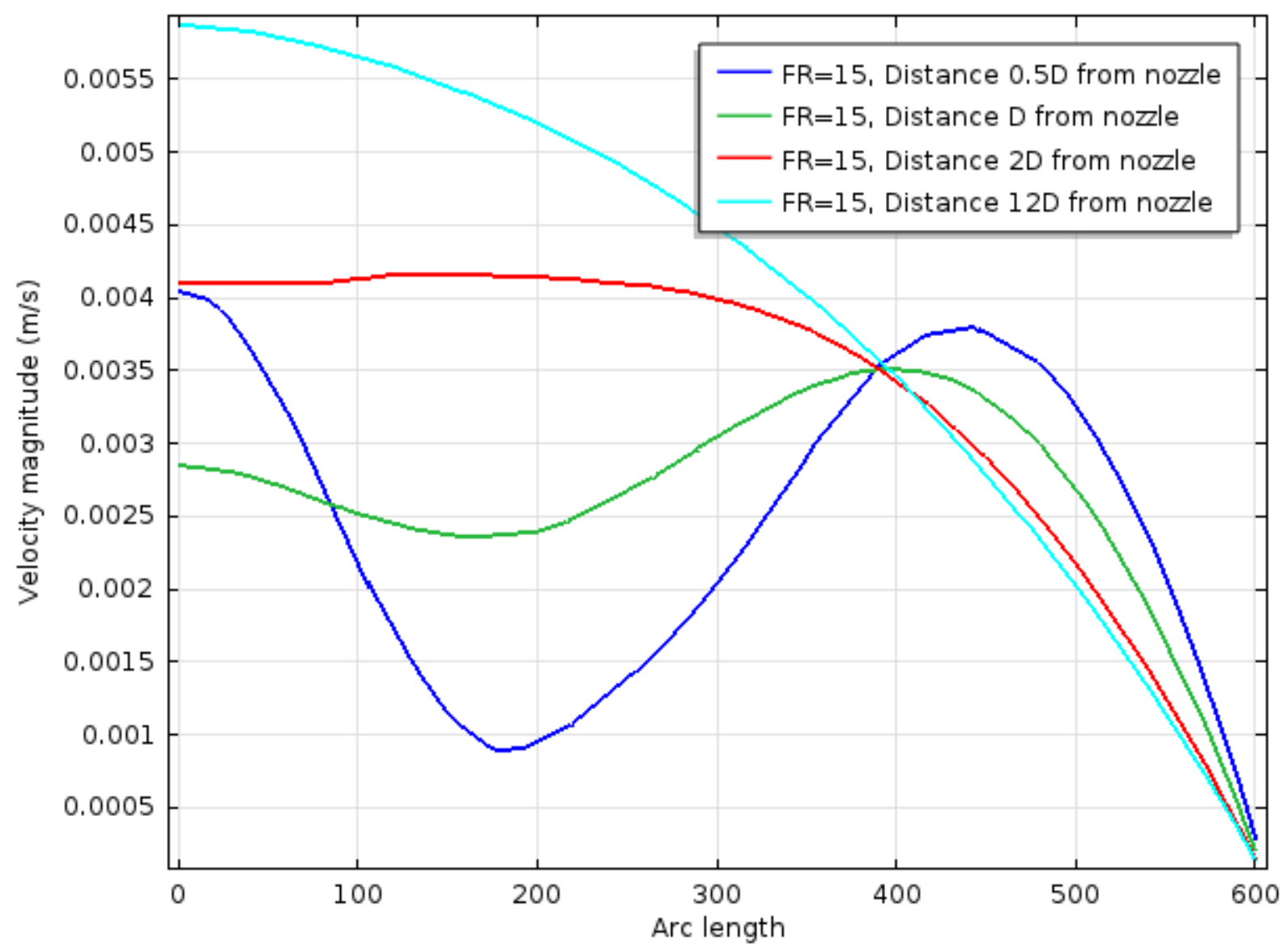

Figure 6. The distribution of velocity over the cross section at $\mathrm{Q}_{\mathrm{w}}=9 \mathrm{ml} \mathrm{h}^{-1}, \mathrm{Q}_{\mathrm{o}}=0.6 \mathrm{ml} \mathrm{h}^{-1}$ and $\mathrm{D}=$ $209 \mu \mathrm{m}$. 


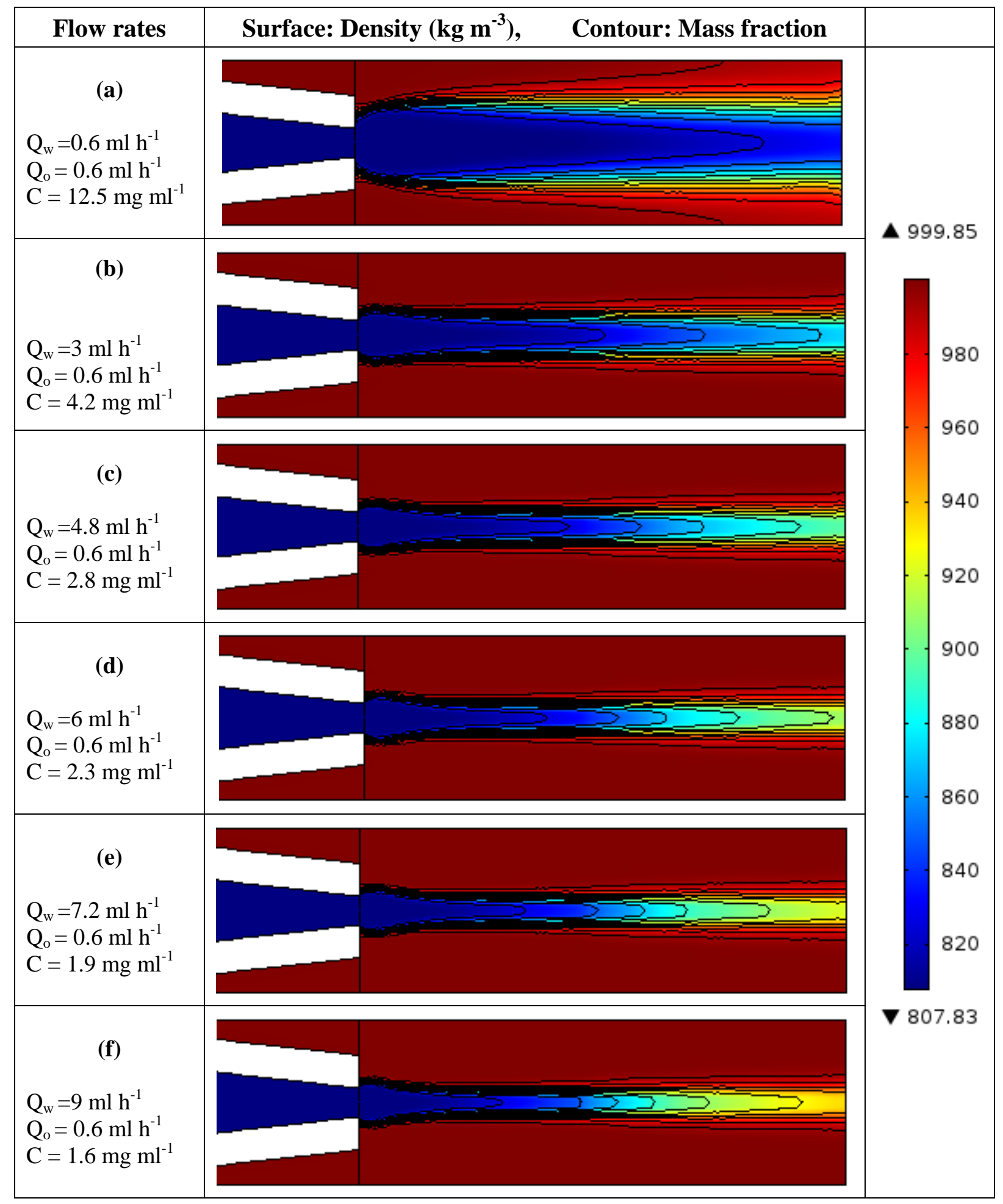

Figure 7. Distribution of fluid densities in co-flow capillary device at the organic phase flow rate, $\mathrm{Q}_{\mathrm{o}}$, of $0.6 \mathrm{ml} \mathrm{h}^{-1}$ and increasing water flow rate, $\mathrm{Q}_{\mathrm{w}}$. The orifice diameter is $\mathrm{D}=209 \mu \mathrm{m}$. $\mathrm{C}$ is the calculated concentration of lipids in the product stream. 

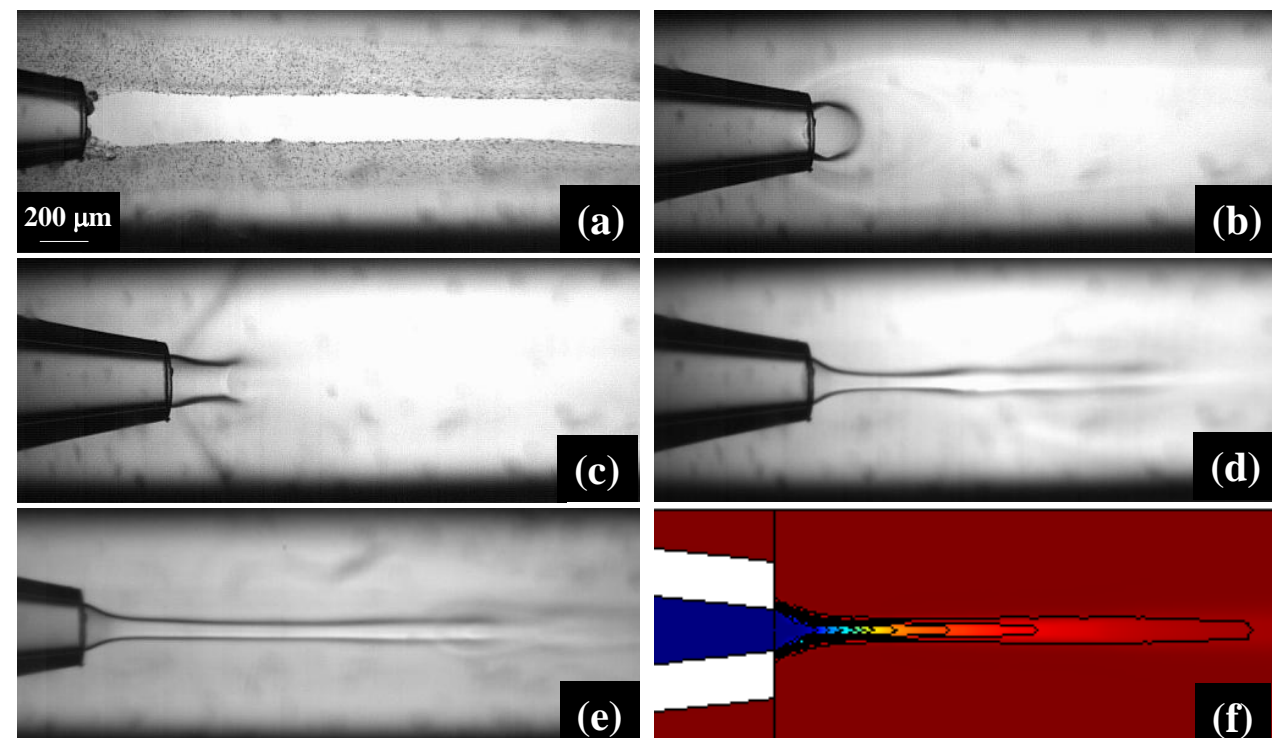

(g)

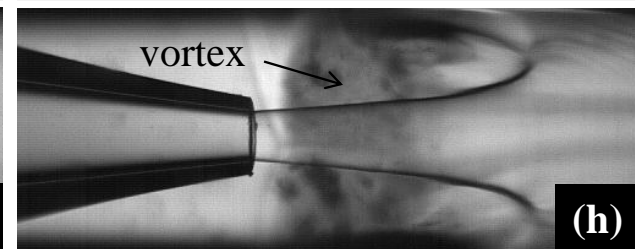

Figure 8. Flow patterns in co-flow capillary device with an orifice size of $209 \mu \mathrm{m}$ at different phase flow rates: (a) $\mathrm{Q}_{\mathrm{w}}=0.6 \mathrm{ml} \mathrm{h}^{-1}, \mathrm{Q}_{\mathrm{o}}=0.6 \mathrm{ml} \mathrm{h}^{-1}$; (b) $\mathrm{Q}_{\mathrm{w}}=5 \mathrm{ml} \mathrm{h}^{-1}, \mathrm{Q}_{\mathrm{o}}=0.6 \mathrm{ml} \mathrm{h}^{-1}$; (c) $\mathrm{Q}_{\mathrm{w}}=15 \mathrm{ml} \mathrm{h}^{-1}$, $\mathrm{Q}_{\mathrm{o}}=0.6 \mathrm{ml} \mathrm{h}^{-1}$; (d) $\mathrm{Q}_{\mathrm{w}}=15 \mathrm{ml} \mathrm{h}^{-1}, \mathrm{Q}_{\mathrm{o}}=0.1 \mathrm{ml} \mathrm{h}^{-1}$; (e) $\mathrm{Q}_{\mathrm{w}}=25 \mathrm{ml} \mathrm{h}^{-1}, \mathrm{Q}_{\mathrm{o}}=0.1 \mathrm{ml} \mathrm{h}^{-1}$; (f) $\mathrm{Q}_{\mathrm{w}}=25$ $\mathrm{ml} \mathrm{h}^{-1}, \mathrm{Q}_{\mathrm{o}}=0.1 \mathrm{ml} \mathrm{h}^{-1}$, CFD simulation; (g) $\mathrm{Q}_{\mathrm{w}}=25 \mathrm{ml} \mathrm{h}^{-1}, \mathrm{Q}_{\mathrm{o}}=12 \mathrm{ml} \mathrm{h}^{-1}$; (h) $\mathrm{Q}_{\mathrm{w}}=25 \mathrm{ml} \mathrm{h}^{-1}, \mathrm{Q}_{\mathrm{o}}=$ $20 \mathrm{ml} \mathrm{h}^{-1}$. 


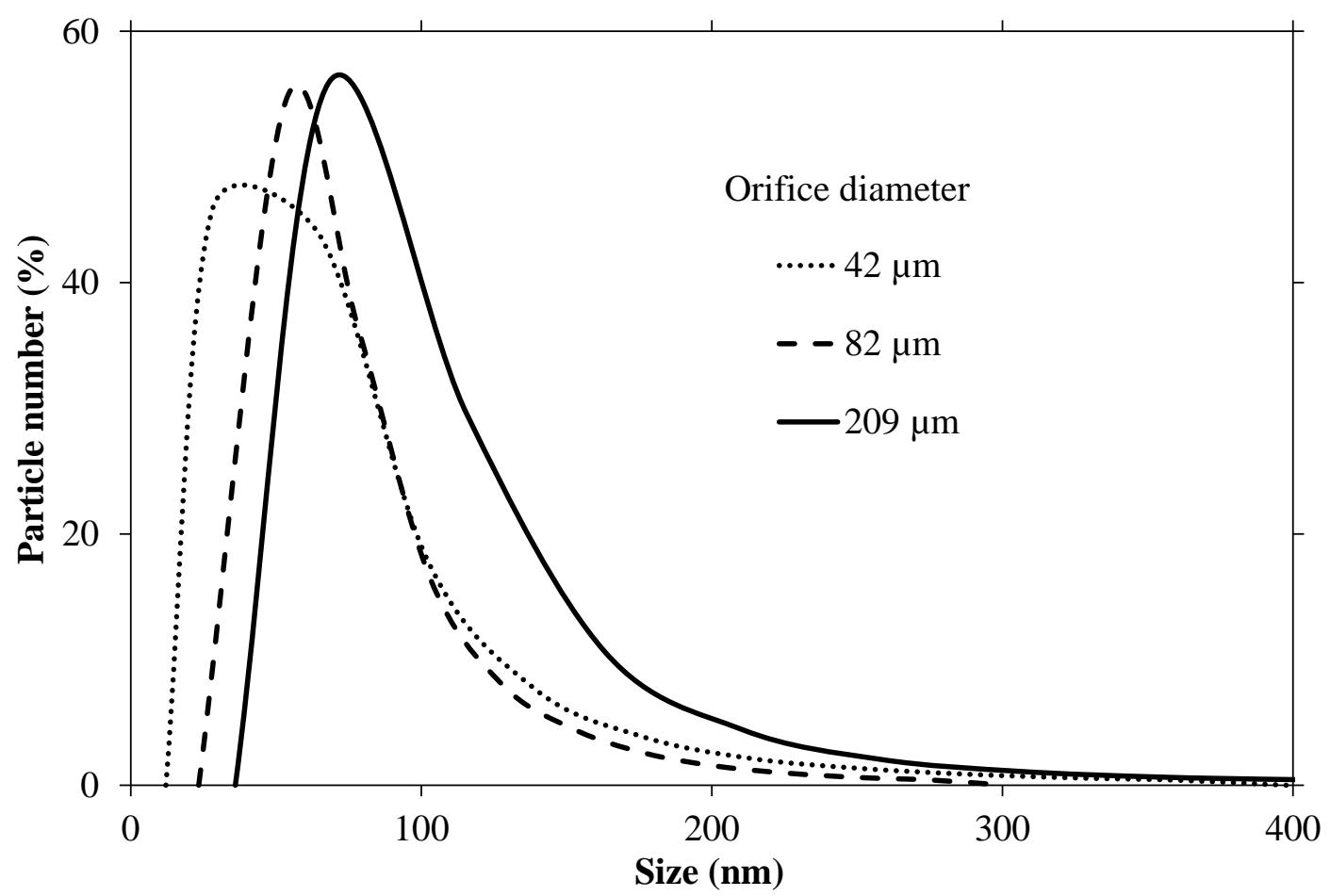

Figure 9. Particle size distribution of liposomal suspensions prepared using co-flow capillary device as a function of orifice diameter. $\mathrm{Q}_{\mathrm{w}}=25 \mathrm{ml} \mathrm{h}^{-1}, \mathrm{Q}_{\mathrm{o}}=5.55 \mathrm{ml} \mathrm{h}^{-1}, \mathrm{Q}_{\mathrm{w}} / \mathrm{Q}_{\mathrm{o}}=4.5$. 
Graphical abstract

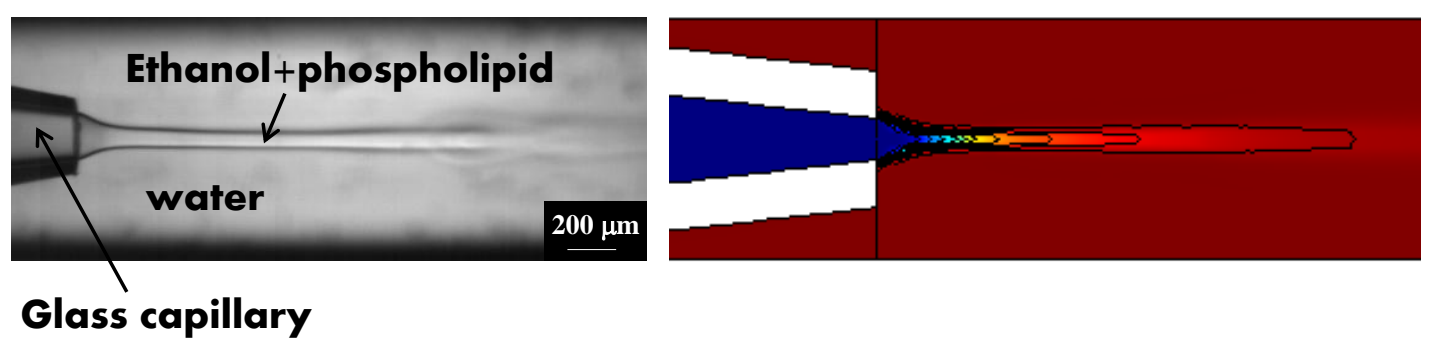

